\title{
An atypical presentation of intrahepatic perforated cholecystitis: a modern indication to open cholecystectomy. Report of a case
}

\author{
Marcello Donati", Antonio Biondi, Francesco Basile and Salvatore Gruttadauria
}

\begin{abstract}
Background: Intrahepatic gallbladder perforation with chronic liver abscess formation was anecdotically reported in the literature. The aim of this work is to report a case of intrahepatic gallbladder perforation and its atypical clinical presentation.

Case presentation: A 62-year-old male patient came to our observation; his medical history showed intermittent fever up to $39-40^{\circ} \mathrm{C}$ of about 2 weeks and anorexia, with an overall weight loss of about $12 \mathrm{Kg}$. Physical examination of the abdomen was negative. An ultrasound of the liver and an abdominal CT angiogram detected a disomogeneous hypoechoic-hypodense area in the 5th segment of the liver. Differential diagnosis between hepatic abscess or gallbladder cancer remained open. A surgical exploration was planned. After laparoscopic exploration, a conversion to open procedure with an atypical resection of the 5 th hepatic segment was performed. Histologic examination of the specimen showed an intrahepatic chronic perforation of the gallbladder with intrahepatic abscess.

Conclusion: To the best of our knowledge, 18 cases have been reported in the literature as a Niemeier type I perforation. Clinical presentation, even in its extreme rarity, is more often acute. Differential diagnosis between gallbladder cancer versus liver abscess remains controversial. Open approach is mandatory in such cases.
\end{abstract}

Keywords: Intrahepatic perforation, Hepatic abscess, Chronic perforation, Chronic cholecystitis

\section{Background}

Perforation of the gallbladder has become a relatively uncommon complication of the natural history of cholelithiasis during acute cholecystitis $(0.8-3.2 \%$ in recent reviews) [1]. It usually bursts with an acute abdomen and must be operated as a surgical emergency before causing septic peritonitis. Gallbladder perforations were classified following Niemeir's proposal of 1934 [2]. Gallbladder can perforate freely in the abdominal cavity or in a neighboring organ causing many different clinical situations [3]. The intrahepatic perforation causing a liver abscess is an extremely rare condition, anedoctically reported in the world literature, even in the rare type II or III perforation (subacute or acute perforation) [4]. Liver abscess caused by gallbladder perforation can be a a life-threatening complication (5.6\% mortality) [5]. Current management of

\footnotetext{
* Correspondence: mdonati@unict.it
Department of Surgery. General and Oncologic Surgery Unit,

*Correspondence: mdonati@unict.it

Vittorio-Emanuele University Hospital of Catania, via Plebiscito 628, 95122 Catania, Italy
}

(c) 2014 Donati et al.; licensee BioMed Central Ltd. This is an open access article distributed under the terms of the Creative Commons Attribution License (http://creativecommons.org/licenses/by/2.0), which permits unrestricted use, distribution, and reproduction in any medium, provided the original work is properly cited. intrahepatic or hepatic abscess is to submit the patient to a percutaneous drainage supported by intravenous antibiotic therapy, when abscess size does not exceed $5 \mathrm{~cm}$, otherwise surgical exploration and drainage remains the first line treatment option for pyogenic liver abscess [6,7]. In cases of gallbladder perforation cholecystectomy is, of course, the treatment of choice, even if in these cases the laparoscopic approach can be problematic [8]. The aim of this work is to report on an intrahepatic type I perforation of the gallbladder leading to a chronic hepatic abscess, causing a very rare and atypical clinical picture.

\section{Case presentation}

A 62-year-old male patient came to our observation with an initial diagnosis of clinically silent long-term inguinal hernia. His medical history showed intermittent fever and anorexia had been present for one year. In detail, the patient reported that over the previous year he had had alternating intermittent fever up to $39-40^{\circ} \mathrm{C}$ of about 2 weeks with quiescence periods of about 20-30 days, 
every few months together with an overall weight loss of about $12 \mathrm{Kg}$. These symptoms were not associated with any other abdominal or thoracic signs. Physical examination of the abdomen was negative. The fever disappeared after an empiric antibiotic therapy with third generation cephalosporins ( 1 gr. for 12 days) was started. Laboratory blood samples obtained when the patient was febrile, showed 12,000 WBC count; liver function tests were in the normal range and serologic screening for Salmonella and Brucella antibodies were negative. Blood cultures, antibiograms and tumor markers were also negative (CEA, CA 19.9).

An ultrasound scan of the liver and an abdominal CT scan (Figure 1A) detected a disomogeneous hypoechoichypodense mass with many internal hyperechoic/hyperdense stones in the 5th segment of the liver. In addition, a cholelithiasis with two small stones in the common bile duct was present. Differential diagnosis between hepatic abscess or gallbladder cancer remained open. An abdominal MRI scan confirmed the above mentioned findings with the evidence of a few bubbles of free air suggesting spontaneous perforation of the gallbladder (B). An ERCP was then performed and the choledocolithiasis was resolved through a papillotomy. Afterwards a surgical exploration was planned. The operation started with a laparoscopic approach to confirm the suspected diagnosis and exclude tumor diagnosis and even more important peritoneal tumor spread that would be a contraindication to radical R0-surgical resection. Laparoscopy showed a bulging lesion involving the gallbladder, liver, great omentum and duodenum, (Figure 2A) while no signs of peritoneal carcinomatosis were detected. We then decided to convert to

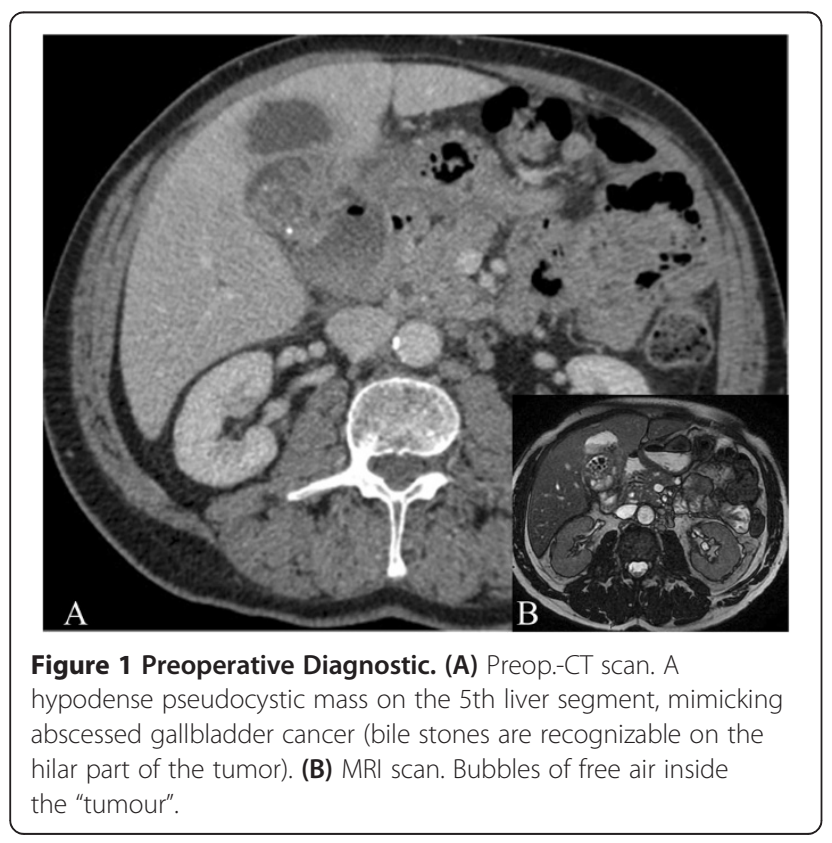

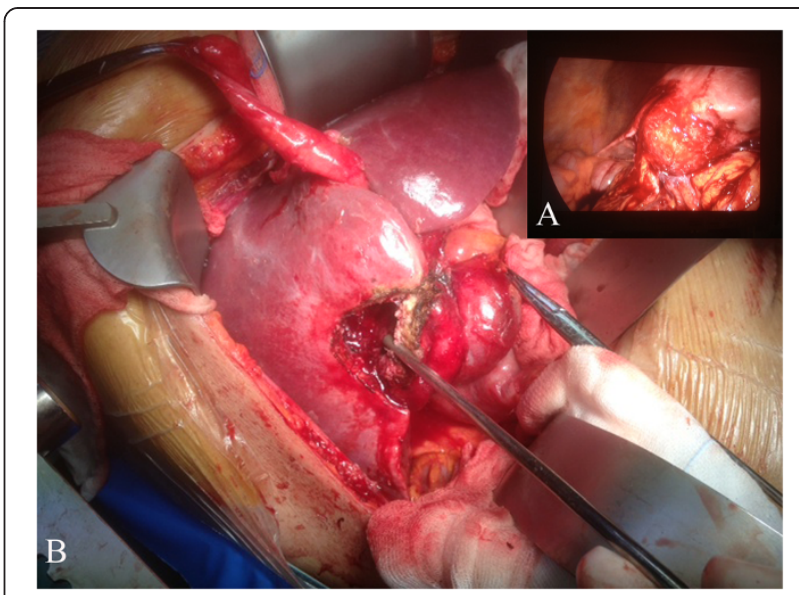

Figure 2 Intraoperative finding: Intrahepatic perforation of the gallbladder. Due to strong hilar adhesions and structure visualization difficulties in laparoscopic view (A), a conversion to "open" approach was decided (B).

open procedure due to uncertain anatomical limits of the lesion in front of the duodenum and the liver hilar structures. After resection of the omental adhesions and the spearing of the duodenum, the bulging was resected enbloc with the gallbladder (Figures 2B-3) and gallbladder bed performing an atypical resection of the 5th hepatic segment. Opening the large abscess we found more than

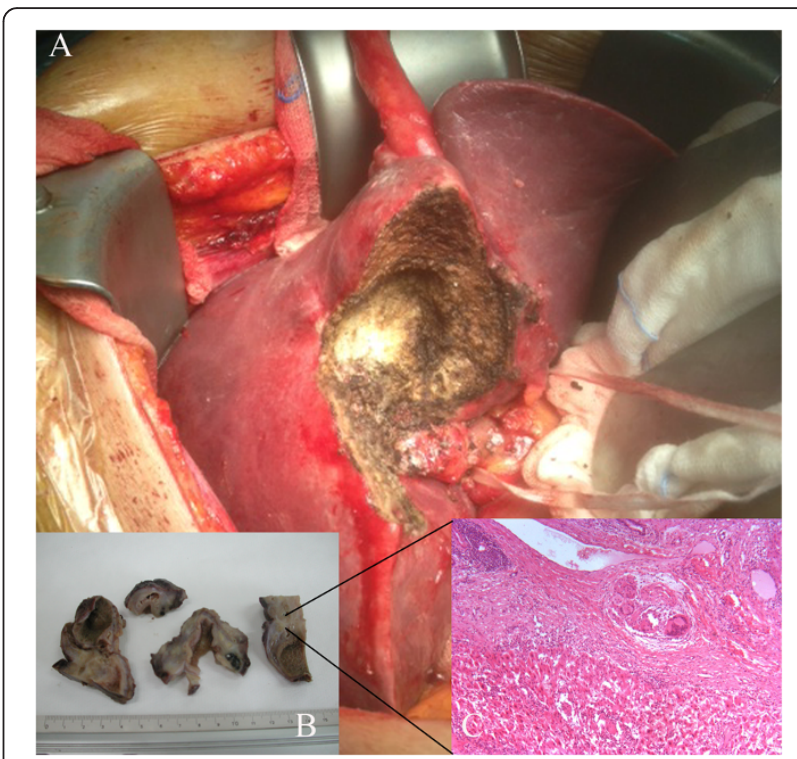

Figure 3 Specimen examination. A) A typical partial resection of the 5th Segment en-bloc with the gallbladder. Intrahepatic position of the gallbladder. B) Macroscopic details of the pathologic specimen: intrahepatic position of the gallbladder. C) Microscopic detail of the specimen (Zoom $10 \mathrm{X}$ ): chronic inflammatory cells (giant plurinucleated cells) mixed with hepatic regeneration nodes in the context of a granuloma under the gallbladder bed, effect of intrahepatic perforation. (Courtesy of Dr. Loredana Villari. Pathology Institute. Vittorio-Emanuele Hospital. Catania.). 
20 biliary stones that had migrated intra-hepatically. The phlogistic nature of the tumor was histologically confirmed by three intra-operative sections (later frozen) and on the definitive histologic examination (Figure 3B, C). The post-operative course was uneventful and the patient was discharged on the 4th post-operative day completely afebrile and in good general condition.

Intra-hepatic gallbladder perforation is generally considered to be a very rare evolution of cholelithiasis, in fact, to date, performing a Pubmed search using as key words: "Intrahepatic abscess, intrahepatic gallbladder perforations, Neimeir's type I perforation, chronic gallbladder perforation" and then using "related articles" and "see reviews" functions of the database, 20 articles were selected but after reading them and avoiding the well-known confusion [9] and mistakes of reporting Neimeir's classification $[4,10]$, only 18 cases of chronic gallbladder perforation with formation of intrahepatic abscess were found to be reported in the literature $[4,11]$; therefore following the original classification they should be considered as Niemeier type I perforations (chronic perforation with fistula) [2]. Despite chronic processes with fistula formation, its clinical presentation, even in its rarity, is more often acute (nausea, vomiting, upper quadrant pain, fever, altered mental status, and septic shock) [12,13], or the consequence of an acute perforation [10]. The diagnosis is usually made by US or CT scan. In our case CT scan was not able to exclude a tumor in the 5th hepatic segment. The lack of acute abdomen symptoms characterized our case and this clinical presentation is to be considered exceptional, while usually such a perforation leads to an emergency operation [4]. This subtle clinical picture can be misleading for the physician causing a delay in obtaining prompt imaging tests. Some reports have highlighted the difficult differential diagnosis between gallbladder cancer versus liver abscess $[12,14,15]$. Because of the very few reports to date, there is no consensus on the standard treatment of such a rare condition $[15,16]$. Simple puncture and drainage in these cases seems to not be an effective option [15]. An endoscopic examination could be an option, even if in this case laparoscopic cholecystectomy could not be performed due to technical reasons (many adhesions, not clear anatomy, high risk of damage to hilar structures). Some Authors question whether this rare condition is more common in patients with an intrahepatic gallbladder [17]. Therefore chronic liver abscess due to gallbladder perforation is a rare evolution of cholelithiasis.

\section{Conclusions}

Intrahepatic gallbladder perforation with abscess formation should be considered an exceptional clinical entity. Despite new diagnostic tools, differential diagnosis with cancer sometimes remains challenging.
It is our opinion that an open approach or early conversion should, in these cases, as in other Niemeier's perforation type I [3], still be the preferred surgical treatment.

\section{Consent}

Written informed consent was obtained from the patient for publication of this Case report and any accompanying images. A copy of the written consent is available for review by the Editor of BMC Surgery.

\section{Abbreviations}

Kg: Kilograms; Gr: Grams; CEA: Carcioembriogenic Antigen; WBC: White blood cells; CT: Computed tomography; US: Ultrasound scan; MRI: Magnetic resonance imaging; ERCP: Endoscopy retrograde colangiopancreatography.

\section{Competing interests}

Marcello Donati, Antonio Biondi, Francesco Basile and Salvatore Gruttadauria have no conflict of interests.

\section{Authors' contributions}

DM wrote the paper and made the final revision. BA collected data and reviewed the text. FB designed the study, chose figures and reviewed the paper. GS coordinated the study, performed the operation, made style and language revision. All authors read and approved the final manuscript.

\section{Acknowledgments}

We would like to thank Dr. Loredana Villari (Pathology Institute. Vittorio-Emanuele Hospital. Catania.) for the images of this work.

Received: 21 April 2013 Accepted: 17 January 2014

Published: 27 January 2014

\section{References}

1. Göbel T, Kubitz R, Blondin D, Häussinger D: Intrahepatic type II gallbladder perforation by a gallstone: in a CAPD patient. Eur J Med Res 2011, 16:213-216

2. Niemeier OW: Acute free perforation of the gallbladder. Ann Surg 1934, 99(6):922-924.

3. Donati M, Cardi F, Brancato G, Calò P, Donati A: The surgical treatment of a rare complication: gallstone ileus. Ann Ital Chir 2010, 81(1):57-62.

4. Kochar K, Vallance K, Mathew G, Jadhav V: Intrahepatic perforation of the gall bladder presenting as liver abscess: case report, review of literature and Niemeier's classification. Eur I Gastroenterol Hepatol 2008, 20(3):240-244.

5. Meddings L, Myers RP, Hubbard J, Shaheen AA, Laupland KB, Dixon E, Coffin C, Kaplan GG: A population-based study of pyogenic liver abscesses in the United States: incidence, mortality, and temporal trends. Am J Gastroenterol 2010, 105(1):117-124.

6. Lok KH, Li KF, Li KK, Szeto ML: Pyogenic liver abscess: clinical profile, microbiological characteristics, and management in a Hong Kong hospital. J Microbial Immunol Inf 2008, 41:483-490.

7. Ch Yu S, Hg Lo R, Kan PS, Metreweli C: Pyogenic liver abscess treatment with needle aspiration. Clin Radiol 1997, 52:912-916.

8. Lo HC, Wang YC, Su LT, Hsieh CH: Can early laparoscopic cholecystectomy be the optimal management of cholecystitis with gallbladder perforation? A single institute experience of 74 cases. Surg Endosc 2012, 26(11):3301-3306.

9. Singal R, Mittal A, Gupta S, Singh B, Jain P: Management of gall bladder perforation evaluation on ultrasonography: report of six rare cases with review of literature. J Med Life 2011, 4(4):364-371.

10. Date RS, Thrumurthy SG, Whiteside S, Umer MA, Pursnani KG, Ward JB, Mughal MM: Gallbladder perforation: case series and systematic review. Int J Surg 2012, 10(2):63-68.

11. Derıcı H, Kamer E, Kara C, Ünalp HR, Tansuğ T, Bozdağ AD, Nazli O: Gallbladder perforation: clinical presentation, predisposing factors, and surgical outcomes of 46 patients. Turk J Gastroenterol 2011, 22(5):505-512.

12. Teebken OE, Bartels M, Fangmann J, Nagel E, Klempnauer J: Chronische Cholezystitis imponierend als Gallenblasen-tumor mit Leberabszess. Swiss Surg 2001, 7(1):28-31. 
13. Alkofer B, Dufay C, Parienti JJ, Lepennec V, Dargere S, Chiche L: Are pyogenic liver abscesses still a surgical concern? A Western experience. HPB Surg 2012, 2012:316013.

14. Singla SL, Garg P, Tahlan RN: Gallbladder carcinoma presenting as liver abscess. Indian J Gastroenterol 1998, 17(2):68.

15. Bakalakos EA, Melvin WS, Kirkpatrick R: Liver abscess secondary to intrahepatic perforation of the gallbladder, presenting as a liver mass. Am J Gastroenterol 1996, 91(8):1644-1646.

16. Kang MS, Park do H, Kwon KD, Park JH, Lee SH, Kim HS, Park SH, Kim SJ: Endoscopic transcystic stent placement for an intrahepatic abscess due to gallbladder perforation. World J Gastroenterol 2007, 13(9):1458-1459.

17. Peer A, Witz E, Manor H, Strauss S: Intrahepatic abscess due to gallbladder perforation. Abdom Imaging 1995, 20(5):452-455.

doi:10.1186/1471-2482-14-6

Cite this article as: Donati et al: An atypical presentation of intrahepatic perforated cholecystitis: a modern indication to open cholecystectomy. Report of a case. BMC Surgery 2014 14:6.

\section{Submit your next manuscript to BioMed Central and take full advantage of:}

- Convenient online submission

- Thorough peer review

- No space constraints or color figure charges

- Immediate publication on acceptance

- Inclusion in PubMed, CAS, Scopus and Google Scholar

- Research which is freely available for redistribution 